\title{
Phylogenetic heterogeneity of the species Acidithiobacillus ferrooxidans
}

Correspondence
Grigorii I. Karavaiko
gregor@inmi.host.ru

\section{INTRODUCTION}

The development of biohydrometallurgy calls for a comprehensive investigation of mesophilic chemolithotrophic microbial communities in extreme econiches characterized by low $\mathrm{pH}$ and high concentrations of metal ions. These communities are able to oxidize $\mathrm{Fe}^{2+}$ ions, sulfur and sulfide minerals and comprise a few phylogenetically unrelated groups of micro-organisms, i.e. some archaea, sulfobacilli, Leptospirillum ferrooxidans and bacteria of the genus Thiobacillus, the taxonomy of which has recently been revised (Kelly \& Wood, 2000). On the basis of the results of $16 \mathrm{~S}$ rDNA sequence analysis, Thiobacillus ferrooxidans, Thiobacillus thiooxidans and Thiobacillus caldus were combined into a new genus, Acidithiobacillus, within the $\gamma$-subclass of the Proteobacteria. Arbitrarily, the species Thiobacillus albertensis was also assigned to this

The GenBank/EMBL/DDBJ accession numbers for the $16 \mathrm{~S}$ rDNA sequences of Acidithiobacillus ferrooxidans strains ATTC $2370^{\top}$, TFN-d, TFI, TFD and TFY are AF465604-AF465608. genus, though the 16S rRNA genes of this species have yet to be sequenced.

The distinguishing feature of the species Acidithiobacillus ferrooxidans is its ability to derive energy from the oxidation of ferrous ions. Various strains of this species have been isolated from natural (rocks, ores and mine waters) and technological (ore concentrates and pulps of the gold and non-ferrous industries) sources. The habitats of A. ferrooxidans strains are geographically extremely diverse and vary in their physico-chemical conditions (presence of particular sulfide minerals and their ratio, $\mathrm{pH}$, temperature and the content of toxic compounds in the liquid phase). This might explain the polymorphism of A. ferrooxidans strains, in terms of both their physiological properties (Tuovinen et al., 1971; Harrison, 1982; Valenti et al., 1989; Leduc \& Ferroni, 1994; Chisholm et al., 1998; Frattini et al., 2000; Ageeva et al., 2001) and genotypic characteristics (Martin et al., 1981; Harrison, 1982; Shiratori et al., 1991; Kondratyeva et al., 1993, 1995; Rawlings \& Kusano, 1994; Rawlings, 1999). The study of the natural 
genotypic and phenotypic variability of bacterial strains is of great importance in discerning the microevolutionary mechanisms of species formation and for their monitoring in biohydrometallurgical processes and in nature.

This study involved a polyphasic genotypic analysis of a large group of $A$. ferrooxidans strains isolated from different habitats and the evaluation of the phylogenetic heterogeneity of these strains.

\section{METHODS}

Strains. Experiments were conducted with 25 strains isolated from natural sulfide ores, their concentrates and dense pulps taken from pilot bacteriochemical reactors used for gold recovery and leaching of non-ferrous metals from sulfide ores and their concentrates (Table 1). All of the novel isolates were Gram-negative, motile, acidophilic, mesophilic, chemolithoautotrophic bacteria that obtained energy by the oxidation of $\mathrm{Fe}^{2+}, \mathrm{S}^{0}$ or sulfide minerals (Karavaiko et al., 1997; Kondratyeva et al., 1999; Ageeva et al., 2001). This allowed us to assign all of the novel isolates to the species A. ferrooxidans. This was supported by the genotypic analysis performed in this work. Nineteen strains, two of which (strains VKM B-458 and VKM B-1160) have been deposited in the All-Russia Collection of Microorganisms, were isolated in the Laboratory of Chemolithotrophic Micro-organisms, the Institute of Microbiology and the Russian Academy of Sciences. Two strains (ATCC $23270^{\mathrm{T}}$ and ATCC 19859) were obtained from the American Type Culture Collection. Four identified strains (TFY, TF-16, TFP and TFR-2) were kindly donated by M. Vrvič, A. Torma, J. Hurtado and E. S. Kalyaeva.

Cultivation. A. ferrooxidans strains were cultivated at $28-30{ }^{\circ} \mathrm{C}$ in batch mode in $250 \mathrm{ml}$ Erlenmeyer flasks containing $100 \mathrm{ml}$ of a medium described by Silverman \& Lundgren (1959). The flasks were shaken at 160 or 240 r.p.m. The initial $\mathrm{pH}$ of the medium was $1 \cdot 8-2 \cdot 0$. The inoculum size comprised $10 \%(\mathrm{v} / \mathrm{v})$ of the growth medium.

DNA isolation. A. ferrooxidans cells for the isolation of DNA were grown in unshaken 51 bottles containing 31 growth medium aerated at a rate of 31 air $\min ^{-1}$. Native DNA was isolated from cells as described by Kondratyeva et al. (1995). In DNA-DNA hybridization experiments, DNA was isolated by the method of Marmur (1961).

DNA analysis. Chromosomal DNA was analysed by PFGE (Kondratyeva et al., 1995). The G+C content of the DNA was determined by the thermal denaturation method. The genome size and the level of DNA-DNA hybridization were evaluated from the DNA renaturation rates (De Ley et al., 1970).

165 rRNA gene amplification and sequencing. 16S rRNA genes were amplified and sequenced using universal prokaryotic primers (Edwards et al., 1989). PCR amplifications were carried out using thermostable BioTaq polymerase (Dialat), according to the manufacturer's instructions. The volume of the reaction mixture was $20 \mu \mathrm{l}$. The PCR program consisted of one cycle of DNA denaturation at $94{ }^{\circ} \mathrm{C}$ for $3 \mathrm{~min}$, primer annealing at $50{ }^{\circ} \mathrm{C}$ for $3 \mathrm{~min}$ and DNA synthesis at $72{ }^{\circ} \mathrm{C}$ for $3 \mathrm{~min}$, five cycles of $94{ }^{\circ} \mathrm{C}$ for $30 \mathrm{~s}$, $50{ }^{\circ} \mathrm{C}$ for $2 \mathrm{~min}$ and $72{ }^{\circ} \mathrm{C}$ for $30 \mathrm{~s}, 30$ cycles of $94^{\circ} \mathrm{C}$ for $30 \mathrm{~s}$, $40{ }^{\circ} \mathrm{C}$ for $30 \mathrm{~s}$ and $72{ }^{\circ} \mathrm{C}$ for $30 \mathrm{~s}$ and a final incubation at $72{ }^{\circ} \mathrm{C}$ for $7 \mathrm{~min}$. PCR products were analysed by electrophoresis in $1 \%$ agarose gel. Bands were visualized by illuminating ethidium bromidestained gels on a BioKom UV transilluminator. 16S rDNA fragments were extracted from agarose gels using a Wizard PCR Preps kit (Promega) and sequenced by the method of Sanger et al. (1977) using a Silver Sequencing kit from the same manufacturer. These procedures were performed according to the manufacturer's instructions, with minor modifications. Electrophoresis was conducted using a Macrophor device (Pharmacia) and an SQ3 Sequencer (Hoefer) at a gel thickness of $0 \cdot 19 \mathrm{~mm}$.

\section{Table 1. A. ferrooxidans strains and their isolation sites}

Strains are grouped according to the type of ore/main sulfide minerals from the isolation site, as described in the text.

\begin{tabular}{|c|c|}
\hline Strain & Isolation site \\
\hline \multicolumn{2}{|c|}{ Gold-arsenic ores and concentrates/FeS ${ }_{2}, \mathrm{FeAsS}, \mathrm{FeS}$} \\
\hline TFD, TFO, TF-1292, TFM, TFN-d, TF 97 & Siberia, Russia \\
\hline TFBk, TFT-92 & Kazakhstan \\
\hline TFT & Kyrghyzstan \\
\hline \multicolumn{2}{|c|}{$\begin{array}{l}\text { Copper-zinc and copper ores, concentrates/ } \mathrm{FeS}_{2} \text {, } \\
\mathrm{CuFeS}_{2}, \mathrm{Cu}_{2} \mathrm{~S}, \mathrm{CuS}, \mathrm{Cu}_{5} \mathrm{FeS}_{4}, \mathrm{ZnS}\end{array}$} \\
\hline TFI & India \\
\hline TFV-1, TFL-2, TFL-3, TFS & Central Urals, Russia \\
\hline VKM B-1160, TFG & Southern Urals, Russia \\
\hline TFN & Altai mountains, Russia \\
\hline TFY & Yugoslavia \\
\hline TF-16 & Canada \\
\hline TFP-15 & Peru \\
\hline ATCC $23270^{\mathrm{T}}$, ATCC 19859 & USA \\
\hline \multicolumn{2}{|l|}{ Other sources/FeS $2, \mathrm{Fe}^{2+}$} \\
\hline TFR-2 & Ferri-ferrous stream on a volcano slope (i.-d. Kunashir), Russia \\
\hline VKM B-458 & Ferri-ferrous stream in Submoscow coalfield, Russia \\
\hline TFWc & Activated sludge from cleaning building, Moscow, Russia \\
\hline
\end{tabular}


Phylogenetic analysis. The $\mathrm{XbaI}$ restriction profiles of native DNA of the strains under study were formalized according to the presence or absence of DNA fragments of a certain length and analysed using the maximum-parsimony algorithm realized in the PHYLIP software package (Felsenstein, 1989) and the neighbourjoining algorithm of the FREETREE program (Pavlicek et al., 1999). A dendrogram based on DNA-DNA hybridization data was constructed using an approximate similarity matrix, whose unknown terms were calculated based on mean values for the cluster, with the aid of the UPGMA algorithm of the PHYLIP software. The 16S rRNA gene sequences of analysed strains were aligned with those of the closest micro-organisms using CLUSTAL W (Thompson et al., 1994). An unrooted phylogenetic tree was generated with the aid of the neighbour-joining algorithm realized in the TREECON package (Van de Peer \& De Wachter, 1994).

\section{RESULTS}

\section{Ecological diversity of strains}

The sources of $A$. ferrooxidans strains (sulfide minerals from different geographical zones) can be divided into three groups (Table 1): (i) gold-arsenic ores and their concentrates; (ii) copper and copper-zinc ores and their concentrates; and (iii) other sources. The major sulfide minerals of gold-arsenic ores are pyrite $\left(\mathrm{FeS}_{2}\right)$, arsenopyrite (FeAsS) and, in ores from the Olimpiadinskoe and Maiskoe deposits, pyrrhotite (FeS). Copper and copperzinc ores from different deposits were mainly polymetallic, except that the copper ore from the Volkovskoe deposit (from which strain TFV-1 was isolated) contained primarily copper sulfide minerals. The major source of $A$. ferrooxidans strains isolated from coal deposits is pyrite. The $\mathrm{pH}$ of ore pulps depends on the composition of sulfide minerals and the activity of bacteriochemical processes in bioreactors. Correspondingly, the amounts of metal ions leached from ores into the liquid phase of ore pulps are different.

\section{Analysis of chromosomal DNA relatedness by PFGE}

PFGE of XbaI-digested DNA of various A. ferrooxidans strains showed that their genomes differ somewhat (Kondratyeva et al., 1993, 1995). Analysis of the DNA restriction profiles of $20 \mathrm{~A}$. ferrooxidans strains by the maximum-parsimony algorithm showed that they fell into three clusters (Fig. 1). However, the confidence levels of most branching points of the dendrogram evaluated by bootstrap analysis were less than $70 \%$. This dendrogram correlated with that generated by the neighbour-joining algorithm (data not presented) with respect to only three branching points, whose bootstrap values exceeded $70 \%$.

\section{The $\mathbf{G}+\mathbf{C}$ content of DNA and the genome size}

The $\mathrm{G}+\mathrm{C}$ content of $A$. ferrooxidans strains varied from $56 \cdot 1$ to $58 \cdot 1 \mathrm{~mol} \%$, and the genome size was $2 \cdot 2-2 \cdot 8 \times$ $10^{6} \mathrm{kDa}$ (Table 2). The most frequent genome size was $2 \cdot 3-2 \cdot 4 \times 10^{6} \mathrm{kDa}$ and the most frequent $\mathrm{G}+\mathrm{C}$ content was about $57 \mathrm{~mol} \%$.

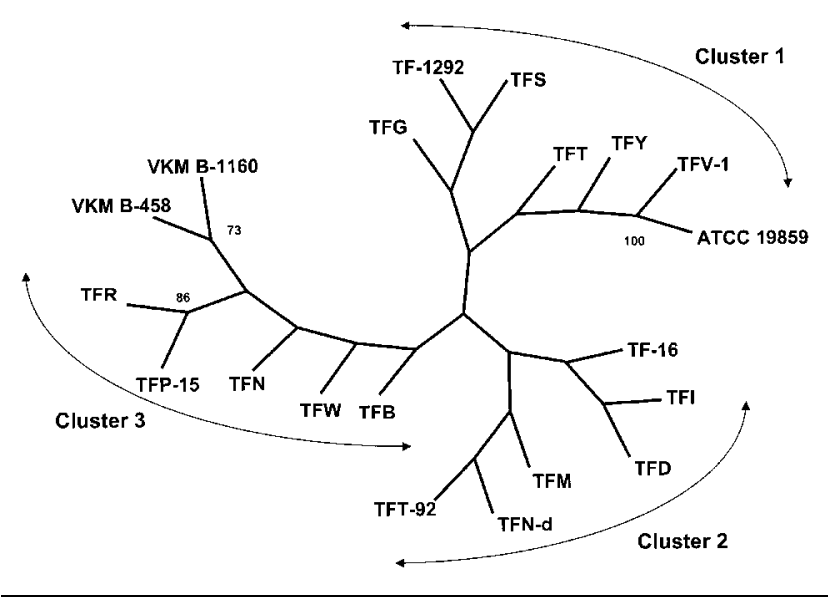

Fig. 1. Phylogenetic tree of $A$. ferrooxidans strains derived from analysis of the lengths of nucleotide fragments obtained by the digestion of native chromosomal DNA with the restriction endonuclease $\mathrm{Xbal}$.

\section{Similarity analysis of the total genomes by DNA-DNA hybridization}

DNA-DNA hybridization analysis of 23 A. ferrooxidans strains with respect to 17 reference strains showed their considerable genetic heterogeneity (Fig. 2). The strains

Table 2. DNA $\mathrm{G}+\mathrm{C}$ content and genome size of A. ferrooxidans strains

\begin{tabular}{|lcc|}
\hline Strain & $\begin{array}{c}\text { G }+ \text { C content } \\
(\mathbf{m o l} \%)\end{array}$ & $\begin{array}{c}\text { Genome size } \\
\left(\times \mathbf{1 0} \mathbf{6}^{\mathbf{6}} \mathbf{k a}\right)\end{array}$ \\
\hline TFD & $58 \cdot 1$ & $2 \cdot 2$ \\
TFV-1 & $57 \cdot 6$ & $2 \cdot 3$ \\
VKM B-458 & $57 \cdot 6$ & $2 \cdot 3$ \\
TF-16 & $56 \cdot 8$ & $2 \cdot 3$ \\
TFS & $57 \cdot 6$ & $2 \cdot 3$ \\
TFG & $57 \cdot 3$ & $2 \cdot 3$ \\
TFP-15 & $56 \cdot 4$ & $2 \cdot 3$ \\
TFN & $57 \cdot 8$ & $2 \cdot 3$ \\
TFWc & $57 \cdot 4$ & $2 \cdot 3$ \\
TFI & $57 \cdot 5$ & $2 \cdot 4$ \\
TFT-92 & $57 \cdot 1$ & $2 \cdot 4$ \\
TFN-d & $56 \cdot 9$ & $2 \cdot 4$ \\
TFT & $57 \cdot 7$ & $2 \cdot 4$ \\
VKM B-1160 & $56 \cdot 5$ & $2 \cdot 4$ \\
TFR-2 & $56 \cdot 3$ & $2 \cdot 4$ \\
TFM & $56 \cdot 9$ & $2 \cdot 4$ \\
TFBk & $56 \cdot 7$ & $2 \cdot 4$ \\
TFL-2 & $57 \cdot 2$ & $2 \cdot 4$ \\
TFO & $57 \cdot 3$ & $2 \cdot 4$ \\
ATCC $23270^{T}$ & $56 \cdot 1$ & $2 \cdot 7$ \\
ATCC 19859 & $57 \cdot 3$ & $2 \cdot 7$ \\
TF-1292 & $57 \cdot 2$ & $2 \cdot 7$ \\
TFY & $57 \cdot 5$ & $2 \cdot 8$ \\
& & \\
\hline
\end{tabular}




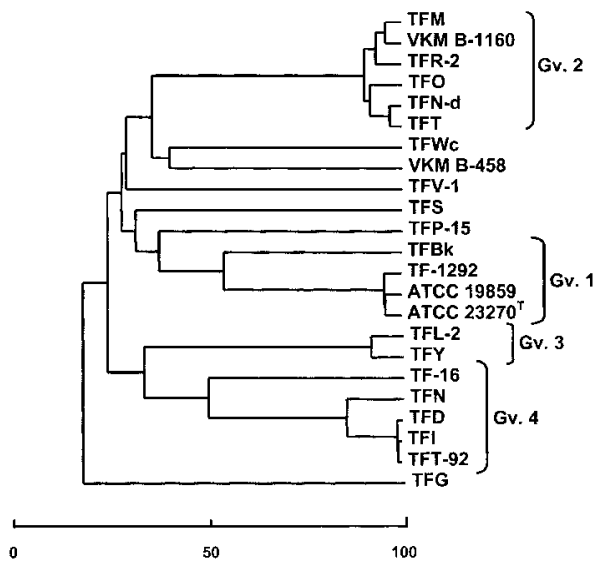

Fig. 2. Approximate relatedness dendrogram of $A$. ferrooxidans strains derived from DNA-DNA hybridization data. The scale bar corresponds to the level of genome similarity.

were divided into four groups characterized by a high degree of genome similarity. Such genome groups are presently called genomovars (Ursing et al., 1995; RosselloMora \& Amann, 2001).

Genomovars are commonly distinguished at a genome similarity level of $70 \%$, which is the typical level of genome similarity within a species (Wayne et al., 1987). However, some authors believe that this value for genome variability within a species should be raised to $50 \%$ (Ursing et al., 1995; Vandamme et al., 1996). According to this criterion, the $A$. ferrooxidans strains under study were divided into four genomovars: (1) strains ATCC $23270^{\mathrm{T}}$, ATCC 19859, TF-1292 and TFBk, with genome similarity levels of 59-96 \%; (2) strains VKM B-1160, TFM, TFR-2, TFO, TFN-d and TFT, with genome similarity levels of 86-97\%; (3) strains TFY and TFL-2, with a genome similarity level of $92 \%$; and (4) strains TF-16, TFN, TFD, TFI and TFT-92, with genome similarity levels of 50-99 \%. The remaining six A. ferrooxidans strains could not be assigned to any of the genomovars, since the similarity of their genomes to one another and to those of the strains comprising the genomovars was only $13-43 \%$.

\section{Phylogenetic analysis of 16S rRNA genes}

We determined nearly complete nucleotide sequences (about $1450 \mathrm{nt}$ ) of the 16S rRNA genes of five A. ferrooxidans strains: the type strain, ATCC $23270^{\mathrm{T}}$ (genomovar 1), and strains TFN-d (genomovar 2), TFY (genomovar 3), TFI and TFD (genomovar 4). A comparative phylogenetic analysis of the $16 \mathrm{~S}$ rRNA genes was performed with respect to a large group of $A$. ferrooxidans strains, two validly described species of the genus Acidithiobacillus (Acidithiobacillus thiooxidans and Acidithiobacillus caldus), a species of this genus that has not yet been validly described ('Acidithiobacillus cuprithermicus') and several strains of this genus whose $16 \mathrm{~S}$ rDNA nucleotide sequences are available from the GenBank database.

According to the results of this analysis, most of the A. ferrooxidans strains, including the type strain, ATCC $23270^{\mathrm{T}}$, constituted a monophyletic cluster with a $100 \%$ bootstrap value (Fig. 3). Within this cluster, A. ferrooxidans strains fell into three phylogenetic groups. The only exception was $A$. ferrooxidans strain IFO 14245, which showed sequence similarity of $97 \cdot 8-98 \cdot 7 \%$ to the $16 \mathrm{~S}$ rRNA genes of the other members of this cluster and fell into none of the groups. The strain Acidithiobacillus sp. SSP, which was not identified to the species level, was assigned to phylogenetic group III, while phylogenetic group IV included the strains Acidithiobacillus spp. NO-8, NO-25, NO-37 and KSC-1, which were also not identified to the species level. The major phylogenetic cluster included not only $A$. ferrooxidans strains but also several strains of $A$. thiooxidans (including the type strain of this species) and the unidentified strain Acidithiobacillus sp. THA, all of which constituted phylogenetic group V. The high bootstrap values of the branching points of the phylogenetic tree (not less than $87 \%$ ) confirm the statistical significance of the above phylogenetic grouping. DNA

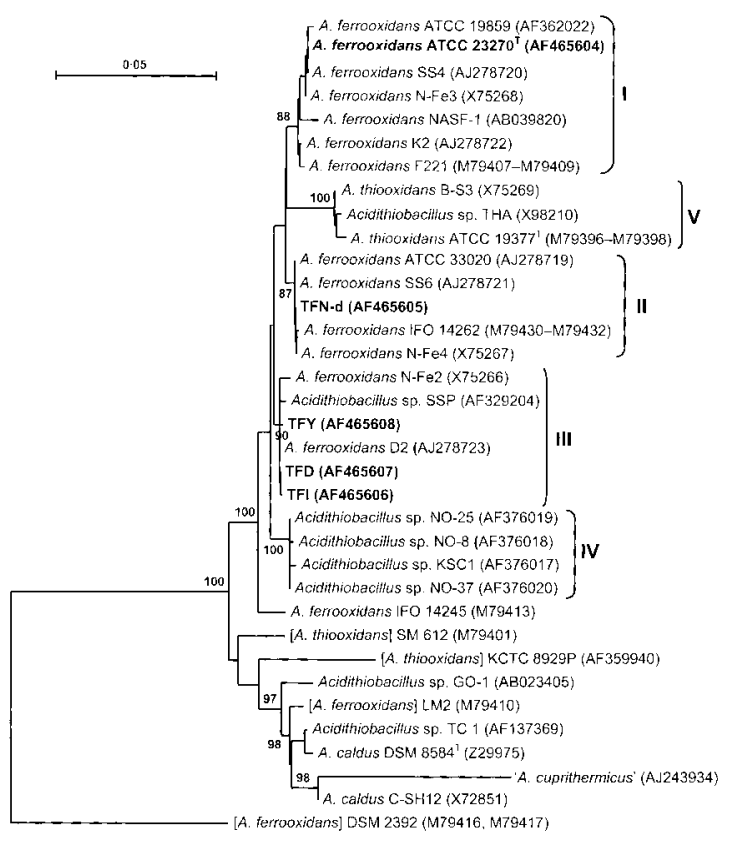

Fig. 3. Unrooted phylogenetic tree of various representatives of the genus Acidithiobacillus showing the position of the A. ferrooxidans strains ATCC $23270^{\top}$, TFN-d, TFI, TFD and TFY. Bar, 5 nucleotide substitutions per 100 nucleotides (evolutionary distance). Numerals near internal branches refer to bootstrap replications (out of 100 resampling) confirming the grouping of the species to the right of the branch. Bootstrap values of less than $85 \%$ are not shown. Square brackets indicate that the current identification of a given strain is not confirmed by $16 \mathrm{~S}$ rRNA gene sequence data. 
similarity levels within and between the phylogenetic groups were respectively $97 \cdot 8-100$ and $96 \cdot 7-99 \cdot 2 \%$. The highest level of intergroup divergence of $16 \mathrm{~S}$ rRNA gene sequences $(1 \cdot 8-3 \cdot 3 \%)$ was observed for phylogenetic group $\mathrm{V}$ of $A$. thiooxidans strains.

The strains of $A$. caldus, including the type strain of this species, constituted another monophyletic cluster with a bootstrap value of $97 \%$. This cluster also included 'A. cuprithermicus' $(91 \cdot 3-94 \cdot 5 \%$ similarity) and Acidithiobacillus spp. strains TC-1 and GO-1. The similarity of the 16S rRNA gene sequences of $A$. caldus strains within this cluster was $98 \cdot 3-99 \cdot 7 \%$, whereas the similarity of this cluster with respect to $A$. ferrooxidans and $A$. thiooxidans strains was considerably lower $(88 \cdot 1-96 \cdot 7 \%)$.

Some A. ferrooxidans and A. thiooxidans strains could not be affiliated with the major phylogenetic cluster. Strains [A. thiooxidans] DSM 612 and [A. thiooxidans] KCTC 8929P took an intermediate position between A. ferrooxidans, A. thiooxidans and A. caldus, showing $88 \cdot 7-96.9 \% 16 \mathrm{~S}$ rRNA gene sequence similarity (square brackets indicate that the current identification of a given strain is not confirmed by $16 \mathrm{~S}$ rRNA gene sequence data). Strain [A. ferrooxidans] LM2 was found to be close to the A. caldus type strain, DSM $8584^{\mathrm{T}}(99 \cdot 2 \%$ similarity). On the basis of $16 \mathrm{~S}$ rRNA gene sequence similarity, three Acidithiobacillus strains, [A. ferrooxidans] DSM 2392 $(79 \cdot 9-88 \cdot 4 \%$ similarity), [A. thiooxidans] KCTC $8928 \mathrm{P}$ $(76 \cdot 1-82 \cdot 2 \%)$ and $[A$. thiooxidans $]$ KCTC $8930 \mathrm{P}$ $(68 \cdot 1-76 \cdot 6 \%)$, could not be assigned to this genus.

All newly studied $A$. ferrooxidans strains belonged to the major phylogenetic cluster, which also included A. thiooxidans strains (Fig. 3). The type strain of A. ferrooxidans fell within phylogenetic group I (99-3-100\% $16 \mathrm{~S}$ rRNA gene sequence similarity), strain TFN-d fell within group II (99.7-99.9\%) and strains TFI, TFD and TFY fell within phylogenetic group III (99·0-100 \%).

\section{DISCUSSION}

Comparative analysis of the 16S rRNA gene sequences of presently known $A$. ferrooxidans strains showed their close phylogenetic relatedness and therefore, their common evolutionary history. According to the results of this analysis, the previously unidentified Acidithiobacillus strains NO-8, NO-25, NO-37, KSC-1 and SSP should be assigned to the species A. ferrooxidans. The common origin of most A. ferrooxidans strains was confirmed by the low level of variability of the nucleotide composition of the DNA and the genome size of the strains studied. At the same time, strains of this species isolated from different habitats exhibited considerable genotypic diversity, which manifested itself as a noticeable divergence of their 16S rRNA gene sequences, a low level of similarity for total DNA and significant differences in the structure of chromosomal DNA revealed by PFGE.
The genotypic heterogeneity of the species A. ferrooxidans is evident even from the analysis of 16S rRNA gene sequences, which are generally much more conservative than the total bacterial genome sequence. This heterogeneity shows up in the grouping of strains belonging to this species into four phylogenetic groups. The data on DNA-DNA hybridization also indicate high genotypic divergence of $A$. ferrooxidans strains, which, with the exception of six independent considerably divergent strains, constitute four groups characterized by a high level of genome similarity (genomovars). These data agree well with the earlier findings of Harrison (1982), who also revealed five groups of $A$. ferrooxidans strains corresponding to genomovars and several strains that could not be affiliated with any of these groups. The high level of DNA-DNA relatedness (96\%) of the genomes of strain ATCC 19859 and the type strain ATCC $23270^{\mathrm{T}}$ suggests that all the allied strains studied by Harrison and us constitute one genomovar and therefore, that the members of this genomovar must be widespread in nature. It can also be suggested that analysis of a larger group of $A$. ferrooxidans strains than those studied by Harrison and us may disclose several additional genomovars among these strains.

Analysis of $16 \mathrm{~S}$ rRNA gene sequences of the strains studied by DNA-DNA hybridization by Harrison (1982) allowed us, in addition, to compare the results yielded by the two methods, and showed that A. ferrooxidans strains ATCC 19859 and F221 from phylogenetic group I belong to one genomovar, while strains IFO 14262, from phylogenetic group II, and IFO 14245, from a separate phylogenetic branch, represent two other genomovars.

Therefore, in general, the results of the DNA-DNA hybridization analysis of $A$. ferrooxidans strains do not contradict the results of analysis of $16 \mathrm{~S}$ rRNA gene sequences, except that the latter analysis combines the representatives of two different genomovars (strain TFY from genomovar 3 and strains TFI and TFD from genomovar 4) into one phylogenetic group. The data presented provide evidence that there are at least two levels of genotypic divergence for A. ferrooxidans. Phylogenetic grouping based on analysis of $16 \mathrm{~S}$ rRNA gene sequences represents a higher level of the genotypic divergence of $A$. ferrooxidans strains, whereas the division of these strains into genomovars in accordance with the species criterion of Wayne et al. (1987) reflects the lower level of their divergence.

The DNA-DNA hybridization analysis of A. ferrooxidans and A. thiooxidans strains carried out by Harrison (1982) showed low genome similarity (not more than $23 \%$ ). Moreover, most of the A. thiooxidans strains studied, including the type strain but excluding strain DSM 612, were found to belong to one genomovar. Analysis of the 16S rRNA gene sequences of $A$. thiooxidans strains, including the type strain, showed that they belong to the same phylogenetic cluster as the majority of A. ferrooxidans strains, constituting a separate phylogenetic 
group equidistant from the other phylogenetic groups of this cluster. These data indicate a close relatedness of the species A. ferrooxidans and A. thiooxidans and allow the suggestion to be made that the latter species has diverged from the former species because of a gradual accumulation of phenotypic differences. According to the findings of Harrison (1982), A. thiooxidans strain DSM 612 does not belong to the same genomovar as other A. thiooxidans strains. Analysis of $16 \mathrm{~S}$ rRNA gene sequences confirmed the incorrect taxonomic identification of this strain, as well as of some other strains such as KCTC 8929P and LM2 (the latter strain probably belongs to the species A. caldus). As for strains DSM 2392, KCTC 8928P and KCTC 8930P, they do not belong to the genus Acidithiobacillus at all.

Analysis of 16S rRNA gene sequences showed that the degree of relatedness of the species A. caldus to A. ferrooxidans and $A$. thiooxidans is lower than the degree of relatedness between the latter two species. The species 'A. cuprithermicus' was affiliated with the phylogenetic cluster of the species $A$. caldus (with a bootstrap value of $98 \%$ ), which casts doubt on the existence of 'A. cuprithermicus' as a separate species.

The genotypic heterogeneity of $A$. ferrooxidans and other species brings up the question of whether they appear as a result of microevolutionary processes within one species or arise through the convergence of several species. The data presented here, in particular those indicating the monophylicity of strains, suggest that their genotypic differences are due to microevolutionary processes. As is evident from the results of analysis of chromosomal DNA by PFGE, these processes may change the location of some genes, while their expression will be retained.

Another problem is the degree of intraspecies variability and the validity of using various physiological, biochemical and molecular genetic methods in the taxonomy of A. ferrooxidans. If we insist that the isolates studied in this work do belong to A. ferrooxidans, then this heterogeneous species is a combination of several groups of strains that have similar phenotypes but differ in their 16S rRNA gene sequences and in the composition of their total genomes. This difficulty is a specific example of the general taxonomic problem concerning agreement between the results of phenotypic and genotypic analyses. The taxonomic division of a phylogenetically heterogeneous species into genomovars and then into separate species occurs as the number of distinguishing phenotypic characteristics of these genomovars increases. It can be suggested that some genomovars of $A$. ferrooxidans may turn out to be separate species, as was the case with the species $A$. thiooxidans.

The DNA restriction profiles, obtained by PFGE, for A. ferrooxidans strains cannot adequately characterize the degree of their genome similarity, as is evident from the differences in the dendrograms (of these strains) that were generated using different algorithms. Even the most statistically significant clusters of these dendrograms do not coincide with genomovars determined by DNADNA hybridization. This can be accounted for by the fact that PFGE is able to detect point mutations at restriction sites, changes in the locations of IST elements (insertion sequences; Yates \& Holmes, 1987) and plasmid-chromosome recombinations, i.e. events that do not alter significantly the nucleotide sequence of the total genome. PFGE is the most sensitive method of DNA analysis applied to the evaluation of intraspecies genome divergence. Unlike chromosomal DNA restriction patterns, the less-sensitive $16 \mathrm{~S}$ rDNA fingerprinting technique fails to differentiate $A$. ferrooxidans strains from each other, but can differentiate them from $A$. caldus strains (Kamimura et al., 2001). In other words, study of the structure of the chromosomal DNA of A. ferrooxidans strains by PFGE cannot evaluate the degree of similarity of the genomes of these strains (and, therefore, the degree of their relatedness) but can detect genetic variability. This method is also of particular value in the individual characterization ('passportization') of microbial strains, especially those used in biohydrometallurgy, and for monitoring natural microbial communities.

It is interesting to ask whether there is a geographical correlation between the diversity of $A$. ferrooxidans strains and their origin. Like Harrison (1982), we failed to reveal such a correlation, although Harrison interpreted his data as an indication of selection of particular genotypes in microeconiches of particular geographical zones. Our data may be interpreted as indicating the existence of a certain degree of correlation between the similarity of the genomes of A. ferrooxidans strains and the mineralogical characteristics of their habitats. For instance, most strains of genomovar 2 (TFO, TFM, TFN-d and TFT) were isolated from gold-arsenic pyrite-arsenopyrite ores and concentrates, although some other strains of this genomovar, such as VKM B-1160 and TFR-2, were isolated from other natural substrates. It is conceivable that large-scale investigations of the genotypic features of indigenous bacterial strains in relation to the properties of their habitats might provide an insight into the role of natural substrates in the microevolution of A. ferrooxidans. This is illustrated by our data on the degree of adaptation of particular strains to oxidation substrates $\left(\mathrm{Fe}^{2+}, \mathrm{S}^{0}\right.$ and sulfide minerals) (Ageeva et al., 2001): each strain attained its own adaptation level determined by the strain's history. At the same time, each indigenous $A$. ferrooxidans strain isolated from an econiche with a particular mineralogical composition of oxidation substrates was characterized by its own chromosomal DNA restriction pattern. In biohydrometallurgical technologies, indigenous strains are always dominant in the pulps of gold and non-ferrous metal ores and concentrates, gradually displacing other introduced strains. Intense oxidative processes in these pulps activate microevolutionary processes and thus promote the formation of new A. ferrooxidans strains. These strains differ in terms of the structure of chromosomal DNA, plasmid composition, optimal $\mathrm{pH}$ and temperature 
values for growth, the growth and substrate oxidation rates, resistance to heavy-metal ions, adaptability and adaptation thresholds. This may explain the failure of attempts to introduce, into natural environments, artificially constructed microbial strains that are highly productive under laboratory conditions.

\section{ACKNOWLEDGEMENTS}

This work was supported by grants nos 99-48360, 00-15-97765 and 01-04-48270 from the Russian Foundation for Basic Research and by grants within the scope of the Russian State Scientific and Technical Programme 'Advanced Methods in Bioengineering'.

\section{REFERENCES}

Ageeva, S. N., Kondrat'eva, T. F. \& Karavaiko, G. I. (2001). Phenotypic characteristics of Thiobacillus ferrooxidans strains. Mikrobiologiya 70, 226-234 (in Russian).

Chisholm, I. A., Leduc, L. G. \& Ferroni, G. D. (1998). Metal resistance and plasmid DNA in Thiobacillus ferrooxidans. Antonie van Leeuwenhoek 73, 245-254.

De Ley, J., Cattoir, H. \& Reynaerts, A. (1970). The quantitative measurement of DNA hybridization from renaturation rates. Eur J Biochem 12, 133-142.

Edwards, U., Rogall, T., Blocker, H., Emde, M. \& Bottger, E. C. (1989). Isolation and direct complete nucleotide determination of entire genes. Nucleic Acids Res 17, 7843-7853.

Felsenstein, J. (1989). PHYLIP - phylogenetic inference package (version 3.2). Cladistics 5, 164-166.

Frattini, C. J., Leduc, L. G. \& Ferroni, G. D. (2000). Strain variability and the effects of organic compounds on the growth of the chemolithotrophic bacterium Thiobacillus ferrooxidans. Antonie van Leeuwenhoek 77, 57-64.

Harrison, A. P. Y. (1982). Genomic and physiological diversity amongst strains of Thiobacillus ferrooxidans and genomic comparison with Thiobacillus thiooxidans. Arch Microbiol 131, 68-76.

Kamimura, K., Wakai, S. \& Sugio, T. (2001). Identification of Thiobacillus ferrooxidans strains based on restriction fragment length polymorphism analysis of $16 \mathrm{~S}$ rDNA. Microbios 105, 141-152.

Karavaiko, G. I., Kondratyeva, T. F., Pivovarova, T. A. \& Muntyan, L. N. (1997). Physiological and genetic characterization of Thiobacillus ferrooxidans strains used in biohydrometallurgy. Prikl Biokhim Mikrobiol 33, 532-538 (in Russian).

Kelly, D. P. \& Wood, A. P. (2000). Reclassification of some species of Thiobacillus to the newly designated genera Acidithiobacillus gen. nov., Halothiobacillus gen. nov. and Thermithiobacillus gen. nov. Int $J$ Syst Evol Microbiol 50, 511-516.

Kondratyeva, T. F., Muntyan, L. N. \& Karavaiko, G. I. (1993). Analysis of restriction patterns of chromosomal DNA of Thiobacillus ferrooxidans strains by pulse electrophoresis. Mol Gen Mikrobiol Virusol 4, 19-22 (in Russian).

Kondratyeva, T. F., Muntyan, L. N. \& Karavaiko, G. I. (1995). Zincand arsenic-resistant strains of Thiobacillus ferrooxidans have increased copy numbers of chromosomal resistance genes. Microbiology 141, 1157-1162.

Kondratyeva, T. F., Pivovarova, T. A., Muntyan, L. N. \& Karavaiko, G. I. (1999). Strain diversity of Thiobacillus ferrooxidans and its significance in biohydrometallurgy. In Biohydrometallurgy and the
Environment. Towards the Mining of the 21st Century, part B, pp. 89-96. Edited by R. Amils \& A. Ballester. Amsterdam: Elsevier.

Leduc, L. G. \& Ferroni, G. D. (1994). The chemolithotrophic bacterium Thiobacillus ferrooxidans. FEMS Microbiol Rev 14, 103120 .

Marmur, J. A. (1961). A procedure for the isolation of deoxyribonucleic acid from microorganisms. J Mol Biol 3, 208-218.

Martin, P. A. W., Dugan, P. R. \& Tuovinen, O. H. (1981). Plasmid DNA in acidophilic, chemolithotrophic thiobacilli. Can J Microbiol 27, 850-853.

Pavlicek, A., Hrda, S. \& Flegr, J. (1999). FreeTree - freeware program for construction of phylogenetic trees on the basis of distance data and bootstrap/jackknife analysis of the tree robustness. Application in the RAPD analysis of genus Frenkelia. Folia Biol (Praha) 45, 9799

Rawlings, D. E. (1999). The molecular genetics of mesophilic, acidophilic, chemolithotrophic, iron- or sulfur-oxidizing microorganisms. In Biohydrometallurgy and the Environment. Towards the Mining of the 21st Century, part B, pp. 3-20. Edited by R. Amils \& A. Ballester. Amsterdam: Elsevier.

Rawlings, D. E. \& Kusano, T. (1994). Molecular genetics of Thiobacillus ferrooxidans. Microbiol Rev 58, 39-55.

Rossello-Mora, R. \& Amann, R. (2001). The species concept for prokaryotes. FEMS Microbiol Rev 25, 39-67.

Sanger, F., Nicklen, S. \& Coulson, A. R. (1977). DNA sequencing with chain-terminating inhibitors. Proc Natl Acad Sci U S A 74, 5463-5467.

Shiratori, T., Inoue, C., Numata, M. \& Kusano, T. (1991). Characterization and cloning of plasmids from the iron-oxidizing bacterium Thiobacillus ferrooxidans. Curr Microbiol 23, 321-326.

Silverman, M. P. \& Lundgren, D. E. (1959). Study on the chemoautotrophic iron bacterium Thiobacillus ferrooxidans. I. An improved medium and harvesting procedure for securing high cell yield. J Bacteriol 77, 642-647.

Thompson, J. D., Higgins, D. G. \& Gibson, T. J. (1994). CLUSTAL W: improving the sensitivity of progressive multiple sequence alignment through sequence weighting, position-specific gap penalties and weight matrix choice. Nucleic Acids Res 22, 4673-4680.

Tuovinen, O. H., Niemela, S. I. \& Gyllenberg, H. G. (1971). Tolerance of Thiobacillus ferrooxidans to some metals. Antonie van Leeuwenhoek 37, 489-496.

Ursing, J. B., Rosselló-Mora, R. A., García-Valdés, E. \& Lalucat, J. (1995). Taxonomic note: a pragmatic approach to the nomenclature of phenotypically similar genomic groups. Int J Syst Bacteriol 45, 604. Valenti, P., Polidoro, M., Buonfiglio, V., Visca, P. \& Orsi, N. (1989). Comparative analysis of Thiobacillus ferrooxidans strains. In Biohydrometallurgy, pp. 187-201. Edited by J. Salley, R. G. L. McCready \& P. L. Wichlacz. Ottawa: CANMET.

Vandamme, P., Pot, B., Gillis, M., De Vos, P., Kersters, K. \& Swings, J. (1996). Polyphasic taxonomy, a consensus approach to bacterial systematics. Microbiol Rev 60, 407-438.

Van de Peer, Y. \& De Wachter, R. (1994). TREECON for Windows: a software package for the construction and drawing of evolutionary trees for the Microsoft Windows environment. Comput Appl Biosci 10, 569-570.

Wayne, L. G., Brenner, D. J., Colwell, R. R. \& 9 other authors (1987). International Committee on Systematic Bacteriology. Report of the ad hoc committee on reconciliation of approaches to bacterial systematics. Int J Syst Bacteriol 37, 463-464.

Yates, J. R. \& Holmes, D. S. (1987). Two families of repeated DNA sequences in Thiobacillus ferrooxidans. J Bacteriol 169, 1861-1870. 